\title{
Desfetichização e romance: Madeleine Férat, de Zola, e Dom Casmurro, de Machado de Assis
}

\section{Daniel Gomes da FONSECA ${ }^{2}$}

O tema dessa notícia de pesquisa é a desfetichização em Madeleine Férat (1866) de Zola e em Dom Casmurro (1899), de Machado de Assis. Embora essas obras sejam desiguais quanto ao momento de produção, uma vez que a primeira pertence à juventude do escritor francês e a segunda à maturidade do brasileiro, há duas justificativas para essa comparação: a primeira é que a crença no hereditarismo, que em Madeleine Férat aparece de forma pura e quase caricatural, nunca abandonará Zola, mesmo em sua maturidade. A segunda justificativa é a coincidência ímpar de motivos literários: ambos os romances tratam de um triângulo amoroso, composto por um casal e o melhor amigo do homem. Em ambas as narrativas o casal tem um filho ou uma filha que, para mal-estar de todos, fica cada vez mais parecido com esse melhor amigo e, nos dois casos, essa crescente semelhança com "o outro" leva ao fim do relacionamento. Os casamentos são motivados por sentimentos autênticos que rompem os preconceitos de classe. Os maridos das duas histórias são membros de frações da elite que estão em declínio e tendem ao parasitismo social. Ambos os maridos sofrem crises de ciúme à Otelo e, como Otelo, reexaminam o passado sob a ótica da desconfiança. As protagonistas, Capitu e Madeleine Férat, são mulheres pobres, consideradas responsáveis pelo fim do relacionamento e, nessa condição, são "demonizadas”. A semelhança principal, no entanto, é a de que a hereditariedade cumpre papel estruturador nos dois romances. Para realizar essa comparação, tratar-se-á do papel da hereditariedade em cada um dos romances, para que ressalte dessa operação o potencial desfetichizador de cada um.

\footnotetext{
1 Notícia de pesquisa apresentada no XX Congresso da Associação Internacional de Literatura Comparada - Paris-Sorbonne (Paris IV) - 18 - 24 de julho de 2013.

${ }^{2}$ Mestrando em Teoria Literária e Literatura Comparada pela Universidade de São Paulo (USP). E-mail: dfonseca@usp.br.
} 
No princípio de Madeleine Férat, Madeleine conhece Jacques, um cirurgião militar extremamente boêmio, e eles vivem juntos durante um ano, quando Jacques a abandona e parte para o Oriente. No caminho, seu navio afunda e todos pensam que ele morreu. Completamente só, Madeleine conhece Guillaume, eles se apaixonam, se casam, sem que Madeleine soubesse que Jacques tinha sido o melhor amigo de Guillaume e sem que Guillaume soubesse que Jacques e Madeleine tinham vivido juntos. Ou seja, marido e mulher conhecem Jacques separadamente e não sabem da relação do outro. Então, ela e Guillaume têm uma filha, chamada Luci, e são felizes durante quatro anos.

Depois desses quatro anos, para a surpresa de todos, Jacques reaparece. Ele havia sobrevivido ao naufrágio e vivido esse tempo no oriente. Guillaume fica sabendo do antigo relacionamento e padece terríveis crises de ciúme. O estranho, no entanto, é que a filha, que foi gerada enquanto Jacques estava no oriente, começa a se parecer com ele cada vez mais, ou seja, apesar de não existir possibilidade biológica alguma, a criança fica cada vez mais parecida com "o outro". Diante disso, o casamento progressivamente se degrada até o livro encerrar-se com o suicídio de Madeleine.

Ao contrário de Dom Casmurro, em que a paternidade da criança é tema para discussão, em Madeleine Férat não há margem pra dúvidas: não há possibilidade de que Luci seja filha do outro. Aí reside o fenômeno hereditário que Zola quis ilustrar, $a$ impregnação fisiológica. A impregnação fisiológica seria "um fenômeno misterioso do sangue" segundo o qual a mulher fica impregnada de seu primeiro amante, a tal ponto que ela pode ter uma criança com outro homem e essa criança se parecer com o primeiro. Essa possibilidade foi defendida, em meados do XIX, por Jules Michelet em $O$ amor, e tentava explicar por que uma criança podia apresentar características divergentes das dos pais sem que houvesse adultério. Por isso o uso da expressão impregnação, que é essa marca indestrutível do primeiro amante, perpetuada por um "misterioso fenômeno do sangue".

No romance, além dessa semelhança entre filha e amigo, a impregnação também se manifesta:

1) Pela sensação de Madeleine de que ela estaria para sempre em posse de seu primeiro parceiro;

2) Em sonhos em que o antigo amante afirma que ela ainda pertence a ele; 
3) Em um delírio, em que Madeleine narra ao marido antigas experiências sexuais que tivera com Jacques;

4) Na ideia de Guillaume de que sua filha fora esboçada nos braços do outro, de que ela tinha sangue do outro e de que ele sofrera um estranho adultério;

5) Mas a manifestação mais espantosa é a de que a própria Madeleine passa a se parecer com o antigo amante. Segundo o narrador, isso acontece porque, em um ano de relacionamento, ela passara por uma educação física com ele, por isso ela repetia as palavras, os gestos, a própria entonação de voz dele até apresentar traços fisionômicos e tomar a expressão do rosto de Jacques.

O narrador nos informa de que Madeleine era ligada ao primeiro amante por fatalidades fisiológicas e que os "membros" dela, a sua face, o próprio olhar e o sorriso transformavam-se, dilatavam-se sob a ação do sangue que ele lhe transmitira. Ainda segundo o narrador, Madeleine seria esposa de seu primeiro homem para sempre, e nem que ela quisesse negar a posse de todo o seu ser, o seu próprio corpo, os seus atos mais íntimos diziam que ela era escrava dessa posse. Vale salientar que, para enfatizar a natureza fisiológica do processo, no campo moral, das emoções, ela nem ao menos ama o antigo amante, ela ama o marido.

Acho que já é possível propor, com base nessa amostra, uma hipótese para o verdadeiro significado da mulher "impregnada": as leis fisiológicas desconhecidas são imagem pseudocientífica com que se propõe que uma mulher não é dona de si, é biologicamente escrava de seu primeiro homem. É uma proposição que reafirma uma visão moralista e sexista, que naturaliza a opressão sofrida pela mulher, é um reflexo fetichizado das relações humanas, uma mistificação, já que essas relações são determinadas por um poder fatalista e alheio aos seres. Para confirmar essa ideia, cito Ernest Seillière:

"em Madeleine Férat, o romancista francês evoluiu para um misticismo pessoal de tradição romanesca (...), a fatalidade orgânica, vista de perto, não é mais que um desvio singular do idealismo proclamando a predestinação erótica, uma fantasia do misticismo diabólico, uma hipótese de possessão amorosa que se vai prestar aos mais ousados desenvolvimentos do misticismo passional" (SEILLIÈRE, 1923, p. 166). 
Isso não poderia deixar trazer consequências estéticas para o romance que, desarticulado, conta com incongruências e inverossimilhanças de diversas ordens, a ponto de não apresentar propriamente enredo ou ação, mas uma sequência de fatos mais ou menos arbitrários que se associam em torno da ilustração de uma tese pseudocientífica. Ou seja, a ilustração da impregnação fisiológica destrói os caracteres e desarticula o romance.

Passemos à hereditariedade em Dom Casmurro, onde tem um papel importante, ainda que de maneira diferente. Madeleine Férat é narrado em terceira pessoa, por um narrador onisciente. Dom Casmurro é narrado em primeira pessoa, a partir da perspectiva de Bento, que é narrador-personagem. A hereditariedade terá relevância para a interpretação de Bento sobre sua própria trajetória e contará com ao menos duas manifestações: a semelhança entre o filho do casal e o melhor amigo e a convicção do narrador de que sua ex-mulher era hereditariamente fadada a ser dissimulada e traidora, ou seja, pérfida por natureza.

Como dissemos, a semelhança entre o filho Ezequiel e o amigo Escobar é base para interpretação de Bento Santiago acerca de sua própria história. Essa semelhança, que é obra do acaso, reveste-se, para ele, da mais inquestionável necessidade: é consequência de adultério cometido por predisposição natural de sua mulher e, nessa qualidade, base para a pena de exílio de Capitu e, quando ela morre, para o enxovalhamento de sua memória. A conclusão do livro traz a famosa síntese com que o narrador caracteriza como inatas as pretensas capacidades de trair e dissimular de sua mulher:

"O resto é saber se a Capitu da praia da Glória já estava dentro da de Matacavalos, ou se esta foi mudada naquela por efeito de algum caso incidente. (...) se te lembras bem da Capitu menina, hás de reconhecer que uma estava dentro da outra, como a fruta dentro da casca" (ASSIS, 1969, p. 248).

Segundo Bento, a Capitu menina, de Matacavalos, já traz a essência da Capitu adulta, da praia da Glória. A Capitu, para ele traidora, já estava na menina; embora não transparecesse, o fruto se escondia no interior da casca. E para Bento o que foi capaz de trazer à tona essa essência, vencendo a também inata capacidade de dissimular? A semelhança entre filho e amigo. Desse modo, Bento reduz suas memórias à narração de 
uma predisposição inata (a traição) percebida por um sinal fortuito (a semelhança), ou seja, reduz sua história à demonstração de um estado de natureza vislumbrado ao acaso.

A relação fruta/casca não é a única imagem de caráter determinista existente no livro. No capítulo "A ópera”, Bento apresenta sua concepção do mundo como teatro e da vida como uma ópera, cuja letra já fora previamente escrita por Deus e a partitura, por satanás. Do descompasso entre a letra escrita por Deus e a partitura do diabo adviriam fatos históricos tais como a revolução francesa e a escravidão moderna, por exemplo.

No capítulo 73, a ideia de predestinação é figurada na imagem do destino como dramaturgo e contrarregra da existência, um destino que designa a entrada das pessoas em cena. Se não bastasse, no capítulo 68 Bento apresenta também uma teoria em que o caráter de cada pessoa é fruto da relação entre pecados e virtudes hereditários, inatos.

Observa-se então que, seja na concepção de mulher traidora por natureza, seja na ópera produzida por deus e satanás, seja na figura do destino como dramaturgo e contrarregra da existência, ou ainda nos pecados e virtudes hereditários, há sempre a ideia subjacente de que, para o narrador Bento Santiago, tudo já está escrito, predestinado, restando aos seres humanos o papel contemplativo de assistir à execução da ópera. Passagens assim levaram Hélio Guimarães a afirmar que Bento quer nos fazer crer que apenas desempenha a função prescrita para ele "no enredo de uma ópera universal, composta em tempos imemoriais" e quer convencer o leitor de que "apenas emprestou a (...) sua voz a uma história pré-existente, que aguardava manifestação no mundo", história cujo verdadeiro autor "seria Deus, ou a natureza, ou o destino" (GUIMARÃES, 2004, p. 221).

Essa concepção de que os seres não constroem sua existência e contam com uma natureza imutável encontrou eco na crítica. Da tentativa de naturalizar o comportamento das personagens deriva a imagem de que Capitu seria uma "mulher fatal", cujo poder de sedução instintivo teria levado o marido à ruína. Essa ideia, disseminada ao longo de todo o livro, está sintetizada nos olhos de Capitu, "de cigana oblíqua e dissimulada" e "de ressaca" que com a força das ondas em momentos de ressaca, traga e destrói tudo aquilo que alcança. essa capacidade pretensamente inata de seduzir e destruir já custou a Capitu os epítetos de: felina (MARTINS, 1939, p.2; MEYER, 2008, p.116; PEREIRA, 1988, p. 240), ondulante (PEREIRA, 1988, p. 240); fera ambiciosa e voluntariosa que mostra as garras (CARVALHO, 1959a, p. 41; MEYER, 2008, p. 117); gata que desfruta 
o prazer de devorar e absorver o rato, com o jogo da volúpia (MATOS, 1939, p. 236); mulher que tem a inocência da aranha que tece sua teia (MATOS, 1939, p. 237; MEYER, 2008, p. 117); fêmea feita de desejo e volúpia (MEYER, 2008, p. 121); mulher que coleia (BOSI, 1999, p. 25; MEYER, 2008, p. 120), que mente por necessidade orgânica (MEYER, 2008, p. 121); animal astuto e lascivo (MESQUITA, 1940, p. 28); que carrega a sombra de seu sexo (MEYER, 2008, p. 111), o estigma da sedução (MESQUITA, 1940, p. 28) e o estigma da maldade (RAMOS, 1969, p. 94); dona de sedução pecaminosa (PEREIRA, 1988, p. 239) e perversidade meticulosa e fria (FONTES, 1939, p. 6); anormal (RAMALHETE, 1939, p. 3); sensual e pervertida (PINHEIRO, 1939, p. 3); pérfida (PUJOL, 1934, p. 247), ardilosa (CARVALHO, 1959a, p. 41; PUJOL, 1934, p. 247); gênio da maquinação (BARRETO, 1980, p. 150), de espírito maquiavélico (MATOS, 1939, p. 236); acautelada e fingida (PUJOL, 1934, p. 247); sinuosa (MARTINS, 1939, p.2); mulher de extraordinária verdade física (DUTRA, 1939, p. 77), que conta com a força planturosa do útero; sua magia religiosa advém da eclosão da vida material, do ímpeto da espécie (MATOS, 1939, p. 236), além de ser dona de superioridade intelectual e sexual e carregar a experiência do instinto (MATOS, 1939, p. 233).

Escravizada às injunções do temperamento (CARVALHO, 1959b, p. 117), Capitu seria plena de fatalidade como as forças cósmicas (MATOS, 1939, p. 235; MESQUITA, 1940, p. 28) e responderia a uma fatalidade incoercível (LEÃO, 1922, p. 2; NAVARRO, 1940, p. 11); mulher falsa de maneira intrínseca e inevitável (BARRETO, 1980, p. 150), seu "império" submete a todos com um "maquiavelismo infantilmente tirânico e implacável” (MOISÉS, 1960, p. 21). Ela foi tratada ainda como Eva diabólica e encantadora (MESQUITA, 1940, p. 28); Eva primitiva que mantém os direitos do instinto e as manhas do egoísmo (MEYER, 2008, p. 11), "espécie de supermulher toda ela só instinto metida na pele de uma pervertida" (PEREIRA, 1991, p. 21), símbolo do mal (GOMES, 1958, p. 155), mulher vampiro que age como morcegos (MORAIS, 1939, p. 65); sereia (idem; BASTIDE, 2010, p. 216); "mulher-marinha" e também "mulher-planta" cujo desenvolvimento torna-se um crescimento vegetal (idem). Daí que se ponha e reponha nessa crítica conservadora, a questão da responsabilidade de Capitu. Se ela age por impulsos atávicos e instintivos, se atinge as raias da inocência animal ou vegetal, se enfim, é amoral e dirigida por fatalidades desconhecidas, como 
responsabilizá-la? (PEREIRA, 1988, p. 239; MEYER, 2008, p. 117; MATOS, 1939, p. 237; MOISÉS, 1960, p. 19; LEÃO, 1922, p. 2; NAVARRO, 1940, p. 11).

Compartilhando dessa visão, o agrônomo e professor de biologia aplicada, Octávio Domingues considerou que a imensa tragédia do livro residia [cito] na "repetição de formas vivas, através das gerações", que ocorre quando "Escobar, repetindo-se biologicamente na outra geração, ressuscita em Ezequiel...”. Para Domingues, é a herança biológica que permite desvendar o mistério psicológico de Capitu. Daí sua tese central: [cito] "Se não fora a hereditariedade não teria havido tragédia, e portanto, onde estaria o romance, ou a sua vida e sua força?" Domingues conclui que Dom Casmurro é romance de tese; e "Machado", muito superior a Zola em "fatalidade hereditária".

Em perspectiva semelhante, Barreto Filho dá ressonância ao determinismo de Bento por meio do caráter inexorável do destino, que [cito] é "a força inapelável que maneja as criaturas" e as combina "segundo leis que não nos é dado conhecer" [fim de citação]. Para ele, Machado pagou uma cota de sacrifício ao naturalismo, e em sua obra [cito] "A filosofia da história que se pode colher (...) é também testemunho da insuficiência da ação humana. O homem não determina a história."

Com isso, procurei mostrar que Dom Casmurro contém elementos naturalistas, tanto na construção do enredo e no papel conferido à hereditariedade, quanto nas concepções que embasam sua construção. Se o livro se resumisse a isso, poderíamos dizer que é um romance de tese como Madeleine Férat, e que, como Madeleine Férat, reflete uma visão fetichizada do mundo, segundo a qual não haveria autoconstrução humana. Acontece que essa perspectiva não resume o sentido de Dom Casmurro, pelo contrário, no conjunto da obra essa perspectiva é desqualificada.

Nessa última parte da minha apresentação, então, eu vou somente mencionar dois aspectos que vêm norteando uma linha crítica que aponta elementos do romance que nos permitem transcender a visão determinista de Bento Santiago.

O primeiro aspecto a que me refiro é a necessidade de considerar a parcialidade de Bento, que é narrador, mas é também personagem. Considerando essa parcialidade, vemos que a interpretação de Bento acerca de sua existência insere-se em um contexto mais amplo e que, nesse contexto, sua interpretação não só não se sustenta, como ganha explicação. O "Otelo brasileiro de Machado de Assis", estudo de Helen Caldwell, é o 
principal marco dessa iniciativa. Aí, Caldwell demonstra a inconsistência da interpretação de Bento e o seu caráter desconfiável como narrador, e oferece as bases para a busca de outra causalidade de enredo, não determinista, por meio da comparação entre Dom Casmurro e Otelo, de Shakespeare.

O segundo aspecto que transcende a visão determinista de Bento é a iniciativa de enraizar historicamente Dom Casmurro. Os trabalhos de John Gledson e Roberto Schwarz caminham nesse sentido e ajudam a perceber como os sentimentos de desconfiança e ciúme, que norteiam a visão distorcida de Santiago, têm raiz na subordinação social da mulher, na escravidão e nas relações de dependência que se estabelecem entre proprietários e não-proprietários. Esse embasamento nas relações sociais permite-nos percebe que o romance transcende a ideia de maldade inata de Capitu, cito John Gledson, “Dom Casmurro não é um romance acerca da maldade pura, sem motivos (...); é um romance sobre um grupo de pessoas que agem de acordo com a lógica de suas condições sociais e familiares. Uma vez compreendidas, bem como a maneira pela qual suas ações caminham juntas para formar o enredo, pode-se começar a enxergar algo do verdadeiro significado do romance".

Para concluir, cabe questionar por que Machado, crítico ferrenho de Zola e Eça de Queirós, estamparia em absoluto primeiro plano uma perspectiva simplista e determinista tributária do naturalismo, deixando em segundo plano uma perspectiva complexa, tecida na inter-relação entre personagens, segundo sua lógica familiar e de classe. Nossa hipótese é a de que, assim procedendo, Machado conjugou a aparência da realidade à sua essência, radicalmente oposta, e assim mostrou a causalidade efetiva que a governa, retratando o mundo como resultado da ação recíproca entre os homens. Nossa hipótese é que reside nessa associação entre aparência e essência da realidade o potencial desfetichizador de Dom Casmurro.

\section{Referências:}

ASSIS, Machado de, Dom Casmurro. Instituto Nacional do Livro, Comissão Machado de Assis: Rio de Janeiro, 1969.

BARRETO Filho, Introdução a Machado de Assis. Agir: Rio de Janeiro, 1980, $2^{\mathrm{a}}$ ed.

CALDWELL, Helen, O Otelo brasileiro de Machado de Assis: um estudo de Dom Casmurro. Ateliê Editorial: Cotia, 2002. 
CARVALHO Filho, Aloysio de, Machado de Assis e o problema penal. Aguiar \& Souza Ltda., Livraria Progresso Editora: Salvador, 1959.

DUTRA, Lia Correa, "Algumas mulheres de Machado de Assis". En: Revista do Brasil, $3^{\text {a }}$ fase. Rio de Janeiro, junho de 1939, n. 12, págs. 74-85.

GLEDSON, John, Machado de Assis: impostura e realismo: uma reinterpretação de Dom Casmurro. Companhia das Letras: São Paulo, 1991.

GOMES, Eugênio, O enigma de Capitu. José Olympio: Rio de Janeiro, 1967.

GUIMARÃES, Hélio de Seixas, Os leitores de Machado de Assis: romance machadiano e público de literatura no século 19. Nankin Editorial : Editora da Universidade de São Paulo: São Paulo, 2004.

LUCAS, Prosper, Traite philosophique et physiologique de l'heredite naturelle. Vol. 2. Chez J. B. Baillière: Paris, 1847.

MARTINS, Luís, "Sofia, Virgília e Capitu”. En: Folha da Manhã. São Paulo, 18 de junho de 1939, pág. 2.

MATOS, Mário, "D. Casmurro". En: Machado de Assis: O homem e a obra: Os personagens explicam o autor. Companhia Editora Nacional: São Paulo, Rio de Janeiro, Recife, Porto Alegre, 1939.

MESQUITA, José de, "De Lívia a Dona Carmo (As mulheres na obra de Machado de Assis)". En: Machado de Assis (estudos e ensaios). F. Briguiet \& Cia: Rio de Janeiro, 1940, págs. 7-30.

MEYER, Augusto, Machado de Assis, 1935-1958. José Olympio / ABL: Rio de Janeiro, 2008, $4^{\mathrm{a}}$ ed.

MORAIS, Raimundo, Machado de Assis. Oficinas gráficas do Instituto Lauro Sodré, Escola Profissional do Estado: Belém, Pará, Brasil, 1939.

NOEMIE; PARRAT, "The mythical theory of impregnation in Zola's Madeleine Férat and l'assommoir". West Virginia University. Philological Papers. FindArticles.com.

En:

$(19 / 07 / 2012)$

http://findarticles.com/p/articles/mi_hb6546/is_52/ai_n29240314/

PEREIRA, Lúcia Miguel, Machado de Assis. Editora da Universidade de São Paulo: São Paulo, 1988.

PINHEIRO, Breno, "Capitu”. En: Folha da Manhã. São Paulo, 18 de junho de 1939, págs. 3 y 5.

RAMALHETE, Olegário, “As mulheres de Machado de Assis”. En: A Gazeta. Vitória, 31 de maio de 1939 , p. 3.

SANTIAGO, Silviano, "Retórica da verossimilhança". En: Uma literatura nos trópicos: ensaios sobre dependência cultural. Rocco: Rio de Janeiro, 2000, $2^{\mathrm{a}}$ ed.

SCHWARZ, Roberto, Duas meninas. São Paulo: Companhia das Letras, 1997.

SEILLIÈRE, Ernest, Emile Zola. Bernard Grasset: Paris, 1923.

ZOLA, Émile, Madeleine Férat. Fasquelle: Paris, 1972. 